\title{
Innovations
}

\section{A reflective space: Supporting local and expatriate patients, developing culturally sensitive mental health practices}

\author{
November 17-18, 2018 \\ Doha, Qatar
}

Medical Humanities in the Middle East Conference

\section{Authors}

Sara Powell ${ }^{*}$; Natalia Gómez-Carlier ${ }^{1+}$

\section{Abstract}

There needs to be a reflective space for mental health professionals, administrative workers, hospital management and policy makers to help shape appropriate intervention and mental health support tailored to the GCC's unique local and expatriate demographic, through a culturally sensitive lens.

Methodology for therapeutic practice for Muslims in the region is generally limited, and psychological theories are predominantly Western. The holy Quran provides Muslims with clear instructions on how to conduct themselves; it is a way of life.' A link which therapists may consider helpful is understanding that a healthy relationship with God is important to the Muslim patient who self-initiates spirituality within the realms of the therapeutic relationship.' In the field of mental health, attachment theory emphasises a need for secure attachment linked to overall mental health, wellbeing, and in the development of healthy relationships. ${ }^{2}$ Having a secure faith has been noted to increase acceptance of treatment. Some patients reported significant challenges in understanding and managing their challenges from a medical and/or spiritual perspective, warranting further discussion. ${ }^{3}$ Clear guidelines ought to be devised taking into account patients' spiritual beliefs and treatment without compromising overall care. There may be notable resistance amongst some Muslims to seek psychological support, requiring clinicians to be aware, enhancing cultural competency. ${ }^{4}$ Statistics on resistance to mental health services as opposed to seeking spiritual guidance regionally will certainly prove helpful. There is also a need to rule
'ATIC Psychological and Counselling Center, Dubai, UAE

*Email: sara@aticarttherapy.com

+Email: natalia@aticarttherapy.com

\section{Cite this article as:}

Powell S, Gómez-Carlier N. A reflective space: Supporting local and expatriate patients, developing culturally sensitive mental health practices. In: Weber AS, Verjee MA, editors. Proceedings of the Ist International Conference on Medical Humanities in the Middle East [Internet]; 2018 Nov 17-18: Doha, Qatar: Innovations in Global Health Professions Education; 2019 March. p. 58-60. (Innovations in Global Health Professions Education; vol. 2019, spec. no.: 1). https://dx.doi.org/10.20421/ighpe2019.01.21

This is an open access article distributed under the terms of the Creative Commons Attribution license CC BY 4.0, which permits unrestricted use, distribution and reproduction in any medium, provided the original work is properly cited. 
out biological conditions at the outset and if at all possible, therapists should ideally seek clarification from an Islamic scholar on Islamic norms and concepts of mental illness through the governing links, as appropriate. ${ }^{5}$ It is imperative for therapists to know when to appropriately apply Islamic psychotherapy.

It is necessary to de-stigmatize mental health within the region and build trust in mental health support, failing which shall lead to delay in intervention and appropriate treatment. Treatment in line with religious principles is considered to be one of the most important psycho-social factors.' Individuals are more likely to seek help when they feel practitioners take into consideration their Islamic values, ${ }^{6}$ thus, giving weight to integrating Islamic psychotherapy within mental health practice and more so when discussing the context of palliative care development in the GCC. Palliative care also requires professionals working in this field to understand ethic-based principles, ${ }^{7,8}$ rooted in religious, cultural origins of the country of practice, taking into account community values at large and the family culture of the patient during end of life care. ${ }^{9}$ Questions need to be addressed if palliative care development is included in the future model of care within the region, guidelines for non-Muslim therapists treating Muslim patients, and deeper understanding of Islamic orientation of the client and community at large. It is strongly recommended that treatment should be Client-led and proceed with utmost care.

In reflection and support of expatriate patients who go through a process of cultural adaptation and acculturation, developing strategies to adapt to the new cultural environment while still attempting to hold on to their own cultural identity, values and beliefs is important. ${ }^{10}$ From a psycho-spiritual perspective, supporting a transpersonal orientation, if it were to arise, may also be appropriate; however, differing spiritual beliefs are to be in line with cultural acceptance and the norms of the country of practice. Spiritual support especially in end of life care can be difficult for people in host countries. Patients may feel further isolated, compounding susceptibility to increased mental health challenges.

Overall, a reflective space for professionals to ponder on how mental health practitioners can tailor treatment programmes is necessary. This should encompass art therapy and expressive therapies and integrating a culturally sensitive model that supports the local patient with an Islamic psychotherapy component, as appropriate. With respect to expatriates, mental health practitioners should become further aware of the unique cultural stresses that expatriates face. Integrating art psychotherapy within treatment models has an added advantage of transcending cultural differences, becoming a unifying visual language for all to benefit from.

Conflicts of interest: None.

Funding sources: None.

\section{References}

1. Sabry WM, Vohra A. Role of Islam in the management of psychiatric disorders. Indian J Psychiatry. 2013 Jan;55(Suppl 2):S205-14. doi:10.4103/0019-5545.105534

2. Bowlby J. Maternal care and mental health: a report prepared on behalf of the World Health Organisation as a contribution to the United Nations programme for the welfare of homeless children. Geneva, Switzerland: World Health Organisation; 1951. 179 p. (Monograph series; vol. 2).

3. Mitchell L, Romans S. Spiritual beliefs in bipolar affective disorder: their relevance for illness management. J Affect Disord. 2003 Aug;75(3):247-57.

4. Hodge DR. Social work and the house of Islam: orienting practitioners to the beliefs and values of Muslims in the United States. Soc Work. 2005 Apr;50(2):162-73.

5. Hall RE, Livingston JN. Mental health practice with Arab families: the implications of spirituality vis-à-vis Islam. Am J Fam Ther. 2006 Mar 1;34(2):139-150. doi:10.1080/01926180500357883

6. Haque A, Keshavarzi H. Integrating indigenous healing methods in therapy: Muslim beliefs and practices. Int J Cult Ment Health. 2014 Jul 
3;7(3):297-314. doi:10.1080/17542863.2013.794 249

7. Bagheri A. Medical futility in Iran. In: Bagheri A, editor. Medical futility: a cross-national study. New Jersey, NJ: Imperial College Press; 2013. p. 263-282.

8. Hamooleh MM, Borimnejad L, Seyedfatemi $\mathrm{N}$, Tahmasebi M. Perception of Iranian nurses regarding ethics-based palliative care in cancer patients. J Med Ethics Hist Med [Internet]. 2013 [cited 2018 Nov 28]; 6:12 [8 p.]. Available from: https://www.ncbi.nlm.nih.gov/ pmc/articles/PMC3885223/

9. Badawi G. Muslim attitudes towards end-oflife decisions. J IMA [Internet]. 2011 Dec [cited 2018 Nov 28]; 43(3):134-9. Available from: https://www.ncbi.nlm.nih.gov/pmc/articles/ PMC3516109/ doi:10.5915/43-3-8602

10. Berry JW. Immigration, acculturation, and adaptation. Appl Psychol. 1997 Jan;46(1):5-34. doi:10.1111/j.1464-0597.1997.tb01087.x

\section{About the authors}

Sara Powell, MA, is from the UK and is the founder of ATIC, an art therapy practice in Dubai, UAE. She has an MA in Art Therapy from LASALLE University, Singapore. Sara has over 9 years' experience and worked on numerous projects in collaboration with Government in Singapore and the GCC. She specializes in women's issues, and child and adolescent related disorders.

Natalia Gómez-Carlier, MAAT, is a ATR-BC Psychologist with a Master's Degree in Art Therapy from the School of the Art Institute of Chicago. Founder of the Colombian Art Therapy Association, she has taught University level courses and has more than 20 years of clinical experience providing culturally sensitive interventions in Bogota, Chicago, New York, Muscat and Dubai. 